SMAD, Rev. Eletrônica Saúde Mental Álcool Drog.

2020 jan.-fev.; 16(1):1-3

DOI: 10.11606/issn.1806-6976.smad.2020.0089

www.revistas.usp.br/smad/

Editorial

\title{
Como as Mídias Sociais influenciam na Saúde Mental?
}

\author{
Samir Antonio Rodrigues Abjaude ${ }^{1,2}$ \\ (D) https://orcid.org/0000-0002-1511-9317
}

Lucas Borges Pereira1,2

(D) https://orcid.org/0000-0002-5957-9286

Maria Olívia Barboza Zanetti ${ }^{1,3}$

(DD https://orcid.org/0000-0002-9551-4711

\section{Leonardo Régis Leira Pereira ${ }^{1}$}

(1) https://orcid.org/0000-0002-8609-1390
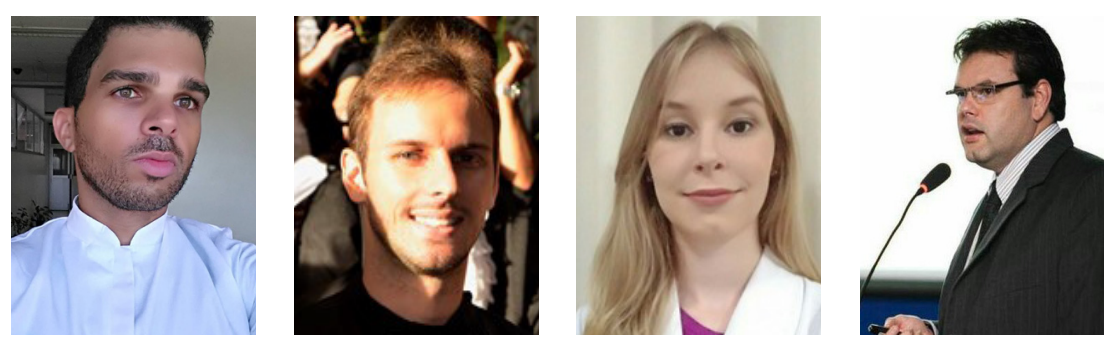

Os problemas de saúde mentais e comportamentais são caracterizados por alterações de pensamento, comportamento ou humor, em associação à angústia ou deterioração do funcionamento psíquico global. Esses problemas são decorrentes de aspectos biológicos associados à fatores culturais e muito influenciados pela sociedade, podendo ser intensificados por uma predisposição do indivíduo(1). Os transtornos mentais, especialmente a ansiedade e a depressão, constituem uma das principais causas de morbidade na sociedade atual, comprometendo as atividades cotidianas do indivíduo, especialmente os relacionamentos sociais. De acordo com a Organização Mundial da Saúde (OMS), pelo menos 350 milhões de pessoas no mundo vivem com depressão(2). A Pesquisa Nacional de Saúde de 2013 apresentou prevalência de depressão em 7,6\% (IC95\% 1,2 - 8,1) da população adulta brasileira(3). Tais números tornaram a saúde mental uma prioridade de saúde pública.

\footnotetext{
${ }^{1}$ Universidade de São Paulo, Centro de Pesquisa em Assistência Farmacêutica e Farmácia Clínica, Faculdade de Ciências Farmacêuticas de Ribeirão Preto, Ribeirão Preto, SP, Brasil.

${ }^{2}$ Bolsista da Coordenação de Aperfeiçoamento de Pessoal de Nível Superior - Brasil (CAPES) - Código de Financiamento 001.

${ }^{3}$ Bolsista do Conselho Nacional de Desenvolvimento Científico e Tecnológico (CNPq), Brasil.
}

\section{Como citar este artigo}

Abjaude SAR, Pereira LB, Zanetti MOB, Pereira LRL. How do social media influence mental health? SMAD, Rev Eletrônica Saúde Mental Álcool Drog. 2020;16(1):1-3. doi: https://dx.doi.org/10.11606/issn.1806-6976.smad.2020.0089. 
O uso de mídias sociais, como Instagram, Facebook ${ }^{\circledR}$, Twitter e YouTube, é um hábito relativamente recente, de modo que ainda tenta-se compreender os efeitos desta nova forma de interação social em diferentes populações. O aumento no tempo dispensado utilizando as redes sociais relaciona-se ao sentimento de isolamento do mundo real, o que pode contribuir para o desenvolvimento de transtornos mentais(4). De acordo com o IBGE, 70\% da população brasileira tem acesso à internet(5), além disso, o Brasil é o segundo país que mais ocupa tempo por dia na internet, estando online em média 9 horas e 29 minutos por dia, sendo que 40\% (3 horas e 34 minutos) deste tempo é utilizado em mídias sociais(6).

O tipo de conteúdo publicado e consumido pelos usuários é ainda mais impactante na saúde mental. Sabese que muitas publicações reforçam o narcisismo, os padrões de vida, de consumo e o status, de forma que têm contribuído com o aumento na prevalência de vários transtornos psiquiátricos, incluindo sintomas depressivos, ansiedade e baixa autoestima(7-8).

Além disso, o usuário também se depara com as famosas "fake News", definidas como informações fabricadas que imitam o conteúdo da mídia de notícias na forma, mas não no processo ou intenção organizacional(9). As "fake News" impactam na saúde mental do usuário das redes sociais, uma vez que são projetadas com o intuito de provocar uma forte resposta emocional do leitor que potencialize a possibilidade de compartilhamento da informação, como raiva, medo, ansiedade e tristeza. Reconhecer uma notícia como "fake News" também pode provocar sentimentos de raiva e frustração, especialmente quando o usuário começa a se sentir impotente diante das frequentes investidas de manipulação da opinião pública por meio de notícias falsas ${ }^{(10-11)}$.

Vale ressaltar também a exposição dos indivíduos ao cyberbullyng, uma prática que se multiplicou nas mídias sociais. $\mathrm{O}$ anonimato e a falta de privacidade e de segurançacontribuem para a disseminação da violência, o que afeta a saúde mental do indivíduo atingido(12).

Na tentativa de minimizar possíveis impactos na saúde mental de seus usuários, algumas das maiores empresas mantenedoras de plataformas de mídias sociais têm se esforçado para criar barreiras e estratégias de prevenção de problemas de saúde mental. Podemos citar como exemplo o aplicativo "Instagram", que retirou a visualização do números de curtidas a fim de diminuir uma "competição" e de valorizar a publicação de materiais com bom conteúdo. Além disso, quando um usuário busca pelas hashtags "ansiedade" ou "depressão", o aplicativo exibe uma mensagem oferecendo ajuda e encaminhando-o para uma rede especializada em oferecer apoio emocional gratuito e em sigilo. Já o "Facebook" tem alavancado esforços para barrar e conscientizar a população sobre o compartilhamento de "fake News".

As empresas e os influenciadores também precisam contribuir na redução desta problemática, utilizando as mídias sociais como ferramentas para a produção de conteúdos que realmente agreguem valor, disseminem informações de qualidade e aproximem as pessoas. Da mesma forma, os usuários das mídias sociais devem preocupar-se com a temática e, em uma estratégia de autocuidado, filtrar os conteúdos a que estão expostos, priorizando aqueles que agregam valor e que não desencadeiam sentimentos prejudiciais. Assim vale ressaltar que tanto o consumo quanto a produção dos materiais deve ser feito com precaução.

Quando falamos sobre a divulgação de conteúdos confiáveis e de qualidade e sobre o combate às "fake News", destaca-se a contribuição dos grupos de pesquisa de instituições científicas. O uso de mídias sociais por pesquisadores transmite a comunicação sobre ciência e atualidades para o universo digital em uma linguagem apropriada, o que facilita o acesso e a compreensão das notícias pela sociedade como um todo(13). Em 2017, o Centro de Pesquisa em Assistência Farmacêutica e Farmácia Clínica da Universidade de São Paulo (CPAFF-USP) criou um rede de informação que se complementa com o uso de diferentes mídias sociais (Instagram, Facebook e YouTube) para divulgar e popularizar a ciência além das fronteiras do mundo acadêmico(14).

Os problemas de saúde mental são preocupações cada vez mais frequente na sociedade, em parte pela utilização inadequada (frequência de utilização e conteúdo consumido) da internet e mídias sociais. Sendo assim, muitas estratégias podem ser adotadas para melhorar este quadro, uma delas é a participação intensiva de instituições e grupos de pesquisa nas mídias sociais por meio de divulgação de conteúdos de qualidade e que promovam o bemestar social.

\section{Referências}

1. World Health Organization. Prevention of Mental Disorders: effective interventions and policy options: summary report [Internet]. Geneva; 2004 [cited Aug 29 2019]. Available from: https://www.who.int/mental_health/evidence/ en/prevention_of_mental_disorders_sr.pdf 
2. World Health Organization. Fact sheet $n^{\circ}$ 369: depression [Internet]. [cited Aug 29 2019]. Available from: https://www.who.int/news-room/fact-sheets/detail/depression

3. Stopa SR, Malta DC, Oliveira MM de, Lopes C de S, Menezes PR, Kinoshita RT. Prevalência do autorrelato de depressão no Brasil: resultados da Pesquisa Nacional de Saúde, 2013. Rev Bras Epidemiol. [Internet]. 2015 Dec [cited Aug 29 2019];18(suppl 2):170-80. Available from: http://dx.doi.org/10.1590/1980-5497201500060015.

4. Primack BA, Shensa A, Sidani JE, Whaite EO, Lin L yi, Rosen D, et al. Social Media Use and Perceived Social Isolation Among Young Adults in the U.S. Am J Prev Med. [Internet]. 2017 [cited Aug 29 2019];53(1):1-8. Available from: https://www.sciencedirect.com/science/article/pii/S0749379717300168

5. Agência de notícias IBGE. PNAD Contínua TIC 2017: Internet chega a três em cada quatro domicílios do país. 2018. [cited Oct 03 2019]. Available from: https://agenciadenoticias.ibge.gov.br/agencia-sala-de-imprensa/2013-agenciade-noticias/releases/23445-pnad-continua-tic-2017-internet-chega-a-tres-em-cada-quatro-domicilios-do-pais

6. We are Social. Global Digital 2019 Reports. [cited Oct 3 2019]. Available from: https://wearesocial.com/globaldigital-report-2019.

7. Pantic I. Online social networking and mental health. Cyberpsychol Behav Soc Netw. 2014 [cited Aug 29 2019];17(10):652-7. doi: 10.1089/cyber.2014.0070

8. Lira AG, Ganen A de P, Lodi AS, Alvarenga M dos S. Uso de redes sociais, influência da mídia e insatisfação com a imagem corporal de adolescentes brasileiras. J Bras Psiquiatr. 2017 [cited Aug 29 2019];66(3):164-7. Available from: http://dx.doi.org/10.1590/0047-2085000000166.

9. Lazer DMJ, Baum MA, Benkler Y, Berinsky AJ, Greenhill KM, Mennczer F, et al. The Science of fake news. Science. 2018;359:1094-96. doi: 10.1126/science.aao2998

10. Singer P.W., Brooking ET. Like War: The Weaponization of Social Media. Publisher: Eamon Dolan/Houghton Mifflin Harcourt; 2018.

11. The American Psychological Association. [Internet] Press Release: Why We're Susceptible to Fake News, How to Defend Against It. San Francisco. [cited Aug 29 2019]. Available from: https://www.apa.org/news/press/ releases/2018/08/fake-news

12. King JE, Walpole CE, Lamon K. Surf and Turf Wars Online-Growing Implications of Internet Gang Violence. J Adolesc Health. [Internet]. 2007 Dec [cited Aug 29 2019];41(6):S66-8. Available from: https://www.sciencedirect.com/ science/article/pii/S1054139X07003667

13. Shimizu H. Uso das mídias sociais na ciência. Agência FAPESP; 2013. [Internet]. [Acesso 3 out 2019]. Disponível em: http://agencia.fapesp.br/uso-das-midias-sociais-na-ciencia/16850/

14. Abjaude SAR, Maduro LCS, Pereira LB, Pereira LRL. Use of social media for Education and Popularization of Science and Pharmaceutical Technologies. Rev Cult Ext USP. [Internet]. 2017; 17:39-49. Available from: http://prceu.usp.br/ revista/wp-content/uploads/2018/04/RCE17_SUPL.pdf 